\title{
Continuing medical education for the rheumatologist
}

\author{
Deborah P M Symmons
}

Johnie has just been appointed as a consultant rheumatologist. It was his sixth interview but he has finally made it-a single-handed consultant in a district general hospital. His nearest rheumatological colleague will be 30 miles away. It has taken 18 years of training since he left school to reach his desired goal. He has taken numerous examinations and written a learned thesis. His sense of achievement is great. He is also apprehensive. Johnie is aware that his non-rheumatological colleagues and junior staff will look to him for definitive pronouncements on the latest treatment for polyarteritis nodosa, current theories on the cause of rheumatoid arthritis, and whether non-steroidal anti-inflammatory creams are efficacious. His patients will expect him to use the most modern diagnostic techniques and treatments. None of his previous education seems to have equipped him for this task of keeping up to date. How will he cope?

Johnie is fictitious, but his dilemma is real. Every consultant rheumatologist needs to continue to acquire and implement new knowledge throughout his working career. Many feel themselves to be poorly equipped for this task of continuing medical education.

Medical education has three phases. The first phase takes place at undergraduate level. Teaching is didactic and exam oriented. After graduation the rheumatologist embarks on a period of higher specialist training culminating in accreditation - the graduate phase of medical education. Continuing medical education is the most recent and least well developed branch of the medical learning process.

It is important to recognise that the educational needs of the consultant rheumatologist are different from those of an undergraduate medical student. Educationalists have distinguished two approaches to conveying information: the 'pedagogic' approach and the 'andragogic' approach. ${ }^{1}$ The pedagogic approach is used for teaching children. The students are dependent on the teacher, have little experience on which to call, and little opportunity to apply the learning. Learning tends to be subject oriented. In the andragogic approach the students are participants and self motivated. They have much experience on which to draw and they wish and are able to apply new skills immediately. Learning needs to be oriented towards perceived problems or areas of ignorance rather than to the subject as a whole. Medical students are usually taught by the pedagogic approach and so are not prepared for adult techniques. The seeds of successful continuing medical education really need to be sown in the undergraduate medical curriculum.

\section{Continuing medical education in the United States}

Continuing medical education is much further advanced in the United States than in the United Kingdom. It is worth looking at the developments in the United States in order to bypass some of the problems they have encountered.

In 1955 the American Medical Association sponsored a study of continuing medical education. ${ }^{2}$ The subsequent report stated that reading, conferences, and communication with colleagues were the main avenues of such education. They advocated the development of a national advisory council to establish standards of evaluation and accreditation, to develop methods to induce participation, and to coordinate efforts. The report speculated that continuing medical education might eventually become mandatory. In 1962 the Dryer report made recommendations for 'a university without walls' with a national curriculum for all medical specialties. ${ }^{3}$ Films, television, and other new educational technology were to be exploited and self assessment examinations needed to be available. Serious efforts to establish national faculties in cardiovascular disease, gastroenterology, and dermatology were made, but the difficulties were overwhelming. ${ }^{4}$ Since then developments have been started predominantly by specialist bodies.

In 1967 the American College of Physicians began a voluntary self assessment programme, which now consists of comprehensive syllabuses, lists of references, an objective test, and a critique of the test questions and answers. The Royal Australasian College of Physicians also produces regular self assessment programmes for its fellows. ${ }^{5}$ In the United States 36 organisations offer programmes which enable practising physicians to review their medical knowledge.

In 1973 the American Board of Medical Specialties agreed to the principle of recertification. By 198613 specialty boards were issuing time limited certificates. In 1987 continuing medical education was a prerequisite for relicensing in 22 states. Six specialty societies and 10 state medical societies require participation in further education for membership.

Unfortunately, the fact that continuing medical education is mandatory has made it big business. Marketing activities are now demanding more attention than the determination of educational needs and designing of appropriate programmes. 
Continuing medical education in rheumatology

In October 1969 La Ligue Internationale contre le Rhumatisme, in cooperation with the XIIth international congress of rheumatology, held a workshop conference on continuing medical education. ${ }^{6}$ This made six recommendations:

1 There should be a central register of the 30 or so journals dealing with rheumatology.

2 Journals should provide reviews as well as specialised research papers.

3 The league should produce a periodic bulletin like the American Bulletin of Rheumatic Diseases. 4 Rapid distribution of proceedings of meetings should occur. There should be more small meetings to discuss a specific subject.

5 There should be improved incentives to attend courses.

6 The importance of training in research methods should be acknowledged.

A further symposium on education in rheumatology was held at the XIIIth international congress of rheumatology in Japan. ${ }^{7}$ It concluded that "leadership for progress in education is best provided by professional rheumatism societies in each country in the form of information bulletins, journals, slide collections, and films'.

The current situation in the United Kingdom Continuing medical education is a field of learning which has, as yet, received little attention in the United Kingdom. Indeed, higher specialist training (graduate education) is much less formalised in the United Kingdom than in the United States, Canada, or Australia. In rheumatology the specialist becomes 'accredited' after a four year period of training in recognised posts. The posts are visited and assessed by the Royal College of Physicians on a regular basis, but there is no formal assessment of the trainees. The last examination taken by most rheumatologists is the membership of the Royal College of Physicians two or three years after graduation. The MRCP is, however, a passport into the realm of specialist rheumatology training rather than an exit visa from it. In 1983 the British Society for Rheumatology (BSR) education committee proposed the introduction of a syllabus for the period of higher professional training and even suggested some type of formal assessment as a prerequisite for accreditation. This idea met with little enthusiasm from either the trainees or the trainers. None of our sister medical specialties has a formal assessment as part of higher specialist training, though the situation is different in the surgical field.

The BSR education committee has a broad remit. It is concerned with rheumatology education at undergraduate, graduate, and specialist level. In the field of continuing medical education it organises an annual half day update on a specific topic and runs courses on paediatric rheumatology, back problems, and advanced rheumatology. The Heberden Committee also takes on the mantle of further education in organising the twice yearly national BSR meetings. There are a number of regional rheuma- tology societies which fulfil an educational function. Some academic units run study days and the pharmaceutical companies produce educational videos, films, and printed material. There is, however, no attempt to coordinate such efforts and the time may have come for the profession to look at the whole question of continuing medical education in a more structured and formal way.

\section{Setting up a continuing medical education programme}

Establishment of an education programme should follow the same principles as setting up any scientific experiment. Firstly, the aims should be stated, the methods used should be assessed, and the results should be evaluated. The aims will be determined by the educational needs of the rheumatologist. Educational diagnosis must precede educational treatment. Thus the first step in setting up a programme is to assess educational needs. ${ }^{8}$ Corporate ignorance could be assessed by means of self administered questionnaires. Computer databases may also be used to identify individual educational needs by documenting types of diagnosis seen, drugs prescribed, tests ordered, procedures performed, and so on.

\section{Principles of effective continuing medical education}

Continuing education must be based on the assumption that although doctors are busy, the great majority would like to improve the quality of care they provide. ${ }^{9}$ An andragogic approach needs to be adopted. Doctors should participate in the development of continuing medical education, and in the setting of priorities. Community needs will, however, also need to be taken into account. There is some evidence that continuing education has more effect when focused on topics that are not of the greatest intellectual interest to the participants. ${ }^{10}$ The most important principle, however, is that continuing education should be enjoyable.

\section{Methods of continuing medical education LECTURES/SEMINARS}

Lectures and seminars are a common means of continuing education. They are probably the best way of keeping the rheumatologist informed of the current state of knowledge, but they do not seem to influence patient care. ${ }^{11}$ This is perhaps because only $6 \%$ of the deficiencies in patient care relate to lack of knowledge. ${ }^{12}$ Such deficiencies are more commonly due to errors such as failure to act on abnormal laboratory results. ${ }^{13}$

\section{SELF STUDY}

Doctors need education aimed at specific areas of their own practice. In particular they often need on the spot information when faced with a patient with a particular difficulty. Telephone calls to colleagues and trips to the library are the current methods used, but in the near future 
electronic databases may have a role. Similarly, computers should help doctors to learn systematically from their own clinical experience.

AUDIT

Peer review can be used successfully for education purposes. Medical audit is soon to become compulsory both in training programmes and in routine hospital practice in the United Kingdom. Information that a doctor performs differently from others tends, however, to encourage regression towards the mean unless the performance can be measured against what is deemed to be 'good practice'.9 Rheumatology might benefit from some consensus views on what constitutes 'good practice' in the management of some common conditions.

\section{READING MATTER}

Once again electronic databases can help doctors track down answers to specific questions. Planning a reading programme to maintain knowledge and expertise may be more difficult. A series called 'postgraduate advances in rheumatology - an independent study course for individual continuing medical education' is currently being produced in the United States and might prove useful to rheumatologists in the United Kingdom.

\section{Incentives to participate}

In the United States continuing medical education is compulsory. In the United Kingdom participation in further education by general practitioners is rewarded financially. Medical students were brought up with the truism 'No test-no study'. Should continuing education in rheumatology in the United Kingdom be encouraged by any of these three methods? Embarrassment, ridicule, and legal action tend to lead doctors to conceal their ignorance. Learning is most likely to take place if it is built in to the clinical system and if the benefits are immediately apparent as improved patient care.
Evaluation of continuing medical education An educational programme can only be judged successful if it achieves its stated aims. Continuing medical education can be assessed in five ways: ( $a$ ) attendance; $(b)$ assessment of participant satisfaction; $(c)$ assessment of increase in knowledge; $(d)$ assessment of improvement in clinical competence; and (e) assessment of improved patient care.

\section{Conclusions}

Johnie, the newly appointed rheumatologist, has perceived a need for continuing education. $\mathrm{He}$ is probably poorly equipped by his previous training to devise his own further education programme. With the benefit of experience from other parts of the globe it would now be possible for the BSR to assess the educational needs of its members and devise appropriate material to meet these needs. This would only be worthwhile, however, if requested by a large proportion of rheumatologists.

1 Knowles M. The adult learner: a neglected species. 2nd ed. Houston: Gulf Publishing Co, 1978

2 Vollan D D. Postgraduate medical education in the United States: a report of the survey of postgraduate medical education carried out by the Council on Medical Education and Hospitals of the American Medical Association, 1952 to 1955. Chicago: American Medical Association, 1955.

3 Dryer B V. Lifetime learning for physicians: principles, practices, proposals. Fournal of Medical Education 1962; 37: p9-91.

4 Manning P R, Petit D W. The past, present, and future of continuing medical education. $\mathcal{F A M A} 1987 ; 258$ : 3542-6. Newble D I. Continuing medical education. Med f A ust 1988; 148: 5-6.

6 Rudd E. Continuing education of the rheumatologist and non-specialised practitioner. Arthritis Rheum 1970; 13: 292-3.

7 Rudd E, Sasaki S. Education in rheumatology. Arthritis Rheum 1974; 17: 647-50.

8 Ward J. Continuing medical education. 2. Needs assessment in continuing medical education. Med F Aust 1988; 148 : 77-80.

9 Muir Gray J. Continuing education: What techniques are effective? Lancet 1986; ii: 447-8.

10 Sibley J C, Sackett D L, Neufeld V, Gerrard B, Rudrick K V, Fraser W. A randomised trial of continuing medical education. $N$ Engl f Med 1982; 306: $511-5$.

11 Haynes R B, Davis D A, McKibbon A, Tugwell P. A critical appraisal of the efficacy of continuing medical education. appraisal of the efficacy

12 Ashbaugh D G, McKean R S. Continuing medical education the philosophy and use of audit. $\mathcal{F A M A} 1976 ; 236: 1485-8$.

13 Williamson J W, Marshall A, Miller G E. Continuing education and patient care research: physicians response to screening test results. $\mathcal{F} A M A$ 1967; 201: 938-42. 